\title{
Pemberdayaan olahraga rekreasi melalui permainan tradisional sebagai upaya pelestarian budaya tradisional Kalimantan selatan
}

\author{
Novri Asri ${ }^{1}$, Endang Pratiwi ${ }^{2}$, Amalia Barikah ${ }^{3}$, Andi Kasanrawali ${ }^{4}$ \\ Universitas Islam Kalimantan Muhammad Arsyad Al Banjari Banjarmasin ${ }^{21,2,3,4}$ \\ Novriasri.na@gmail.com ${ }^{1}$,pratiwiendang@uniska-bjm.ac.id ${ }^{2}$, Amaliabarikah29@gmail.com³ \\ kasandrawali89@gmail.com ${ }^{4}$
}

\begin{abstract}
Abstrak
Permainan tradisional sebagai salah satu kebudayaan bangsa yang tersebar hingga keseluruh pelosok negeri perlahan hilang dan sulit ditemui di masyarakat. Hal ini terjadi akibat dari perkembangan zaman yang semakin modern, sehingga anak-anak, remaja bahkan orang dewasa perlahan beralih dari permainan tradisional ke permainan modern berupa game onlinelelektronik. Permainan game online dominan menggunakan mata dan tangan saja, sehingga lebih banyak memberi dampak negatif bagi perkembangan motorik dan sosial anak, berbeda dengan permainan tradisional yang melibatkan semua anggota tubuh yang memberikan manfaat besar, yaitu menjadikan tubuh lebih sehat, kuat dan bugar. Selain itu juga dampak lain dari tergerusnya permainan tradisional bagi remaja saat ini adalah, minimnya moral remaja dalam kehidupan bermasyarakat. Banyak remaja saat ini yang tidak perduli dan tidak menghargai orang lain. Pelecehan seksual, perkelahian antara siswa dengan guru dan percakapan vulgar anak dan remaja menjadi hal yang dianggap biasa. Melalui kegiatan Pengabdian Kepada Masyarakat ini, kami akan mengenalkan kembali permainan tradisional kepada masyarakat Kota Banjarbaru. Metode yang akan kami gunakan demi tercapainya tujuan kegiatan ini adalah dengan cara memberikan edukasi permainan tradisional berupa sosialisasi permainan tradisional serta melakukan praktik langsung bermain permainan tradisional di Komplek GCIP Hero, Kota Banjarbaru. Kegiatan ini diharapkan dapat menumbuhkembangkan kembali minat serta rasa cinta anak-anak dan remaja Kota Banjarbaru terhadap warisan budaya bangsa yaitu permainan tradisional. Menumbuhkembangkan kembali moral dan nilai-nilai kehidupan bermasyarakat serta menjadi wadah hiburan dalam menghilangkan rasa bosan dan stres akibat rutinitas sehari-hari bagi semua anak, remaja dan seluruh masyarakat Kota Banjarbaru.
\end{abstract}

Kata kunci:Permainan Tradisional, Olahraga Rekreasi, Kalimantan Selatan.

\section{Empowerment Of Recreational Sports Through Traditional Games As The Preservation Of The Traditional Culture Of South Kalimantan}

Traditional games as one of the nation's cultures that spread throughout the country are slowly disappearing and are difficult to find in society. This occurs as a result of the development of increasingly modern times, so that children, teenagers and even adults slowly switch from traditional games to modern games in the form of online/electronic games. The dominant online game play uses the 
eyes and hands only, so that it has more negative impacts on the motoric and social development of children, in contrast to traditional games that involve all members of the body which provide great benefits, namely making the body healthier, stronger and fitter. Besides that, another impact of the erosion of traditional games for adolescents today is the lack of moral adolescents in social life. Many teenagers today do not care and do not respect other people. Sexual harassment, fights between students and teachers and vulgar conversations between children and adolescents are considered normal. Through this Community Service activity, we will reintroduce traditional games to the people of Banjarbaru City. The method we will use in order to achieve the objectives of this activity is by providing education on traditional games in the form of socializing traditional games as well as direct practice playing traditional games at the GCIP Hero Complex, Banjarbaru City. This activity is expected to re-develop the interest and love of the children and youth of Banjarbaru City towards the nation's cultural heritage, namely traditional games. Re-develop morals and values of social life and become a place of entertainment in eliminating boredom and stress due to daily routines for all children, adolescents and the entire community of Banjarbaru City.

Keywords:Traditional Games, Recreational Sports, South Kalimantan.

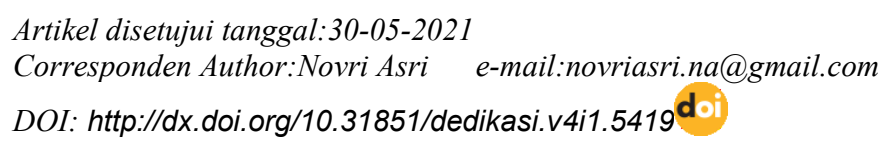

\section{PENDAHULUAN}

Karang Taruna adalah satu dari sekian banyak organisasi kepemudaan yang ada di Indonesia. Berdasarkan Peraturan Menteri Sosial Pasal 1 angka 1, Nomor 77/HUK/2010 tentang Pedoman Dasar Karang Taruna menyebutkan bahwa, Karang Taruna merupakan organisasi sosial kemasyarakatan sebagai wadah dan sarana pengembangan setiap anggota masyarakat yang tumbuh dan berkembang atas dasar kesadaran dan tanggung jawab sosial dari, oleh dan untuk masyarakat terutama generasi muda di wilayah desa/kelurahan terutama bergerak di bidang usaha kesejahteraan sosial. Hal ini kembali ditegaskan dalam Pasal 4 Permensos 77/2010: "Karang Taruna berkedudukan di desa/kelurahan di dalam wilayah hukum Negara Kesatuan Republik Indonesia.”

Sebagai organisasi kepemudaan, Karang Taruna berpedoman pada Pedoman Dasar dan Pedoman Rumah Tangga yang telah diatur, baik tentang struktur pengurus dan masa jabatan di masing 
-masing wilayah mulai dari Desa/Kelurahan sampai pada tingkat Nasional. Semua ini wujud dari regenerasi organisasi demi kelanjutan organisasi serta pembinaan anggota Karang Taruna baik dimasa sekarang maupun masa yang akan datang. Karang Taruna beranggotakan pemuda dan pemudi yang berusai 1735 tahun. Karang Taruna didirikan dengan tujuan memberikan pembinaan dan pemberdayaan kepada para remaja, misalnya dalam bidang keorganisasian, ekonomi, olahraga, keterampilan, advokasi, keagamaan dan kesenian. Karang taruna merupakan organisasi kepemudaan yang termasuk sebagai Lembaga Kemasyarakatan. Sebagaimana yang tercantum pada Peraturan Menteri Dalam Negeri Nomor 5 Tahun 2007, Pasal 1 angka 14 tentang Pedoman Penataan Lembaga Kemasyarakatan, yang berbunyi: "karang taruna adalah Lembaga Kemasyarakatan yang merupakan wadah pengembangan generasi muda yang tumbuh dan berkembang atas dasar kesadaran dan rasa tanggung jawab sosial dari, oleh dan untuk masyarakat terutama generasi muda di wilayah desa/kelurahan atau komunitas adat sederajat dan terutama bergerak di bidang usaha kesejahteraan sosial, yang secara fungsional dibina dan dikembangkan oleh Departemen Sosial".

Sebagai organisasi sosial kemasyarakatan, sudah seharusnya setiap desa ataupun kelurahan yang ada di Indonesia termasuk di Kalimantan Selatan memberdayakan dengan maksimal fungsi dari organisasi karang taruna. Dengan demikian maka tujuan dari organisasi karang taruna akan terwujud dan memberikan manfaat yang nyata kepada masyarakat. Sesuai dengan tujuan dari organisasi karang taruna yaitu untuk membina dan memberdayakan para remaja, dalam bidang keorganisasian, ekonomi, olahraga, keterampilan, advokasi, keagamaan dan kesenian, maka Karang Taruna Puskopad Kota Banjarbaru bermaksud untuk membina remaja komplek tersebut dalam bidang keolahragaan yaitu memberdayakan permainan tradisional. Mengingat olahraga permainan tradisional di masa sekarang ini semakin hilang di lapisan masyarakat, anak-anak, remaja bahkan orang tua-pun sudah mulai meninggalkan dan melupakan olahraga permainan tradisional.

Permainan tradisional merupakan permainan yang berasal dari nenek moyang diwariskan secara turun temurun dari generasi kegenerasi. Permainan tradisional sudah menyebar dan menjadi budaya di seluruh pelosok Indonesia, hal inilah yang menjadi salah satu ciri khas dari setiap daerah masing-masing. Kalimantan Selatan selain dikenal sebagai kota seribu sungai juga merupakan kota yang kaya akan ragam masyarakat dan budaya, salah satunya adalah budaya permainan tradisional yang ada disetiap daerah provinsi Kalimantan Selatan. Diera sembilan puluhan, permainan tradisional cukup populer di Kalimantan Selatan, khususnya di Kota Banjarbaru, misalnya seperti permainan balogo, isutan jarat, batewah, bakiak, bagasing, enggrang, dedakuan dan masih banyak lagi permainan tradisional lainnya.

Dizaman yang serba canggih seperti saat ini, permainan tradisional 


\section{WAHANA DEDIKASI}

sudah mulai dilupakan oleh anakanak, remaja dan orang dewasa. Banyak anak-anak dan remaja masa kini beralih ke permainan yang lebih modern yaitu permainan game online atau permainan elektronik (Putra et al, 2020). Dampaknya adalah, permainan tradisional menjadi hilang dan tidak dikenali lagi oleh masyarakat. Padahal dilihat dari manfaatnya, permainan modern berupa game online ataupun game elektronik lebih banyak memberikan dampak negatif dibandingkan positif. Karena aktivitas fisik yang dilakukan saat bermain game online ataupun game elektronik hanya mengandalkan tangan dan mata. Selain itu juga pola hidup orang yang bermain game online menjadi tidak teratur, mereka bisa bertahan bermain game online hingga berjamjam bahkan lupa waktunya tidur, makan, belajar dan beribadah. Selain itu juga bagi mereka yang sudah kecanduan bermain game online, mereka rela melakukan apa saja demi permainan tersebut, tidak menutup kemungkinan berlaku kasar kepada sesama teman bahkan kepada orang tua mereka lakukan demi bermain game online.

Disisi lain permainan game online juga bisa menyebabkan penyakit yang cukup serius seperti yang sekarang ini banyak dialami oleh remaja-remaja yang sudah kecanduan dalam bermain game online. Seperti yang dilansir dari Jurnal Ilmiah Farmasi Imelda, vol 1 nomor 1 tahun 2017 yang berjudul "Hubungan Tingkat Kecanduan Game Online Terhadap Kejadian Astenopia pada Pelajar SMA Kota Medan" diungkapkan bahwa salah satu dampak dari kecanduan bermain game online adalah penurunan kondisi penglihatan, biasanya berawal dari mata lelah (astenopia) dan kering. Astenopia merupakan sekumpulan gejala pada mata dengan manifestasi yang tidak spesifik, seperti mata perih, berair, nyeri kepala dan penglihatan ganda.

Kecanduan game online dapat memberikan dampak negatif atau bahaya bagi remaja yang mengalaminya. "Dampak yang akan muncul akibat kecanduan game online meliputi lima aspek, antara lain aspek kesehatan, aspek psikologis, aspek akademik, aspek sosial dan aspek keuangan" (King \& Delfabbro, 2018). Hal ini senada dengan apa yang disampaikan oleh Ghuman \& Griffiths (2012) yaitu "masalah yang bisa ditimbulkan dari bermain game online yang berlebihan adalah, kurang peduli terhadap kegiatan sosial, kehilangan kontrol atas waktu, menurunnya prestasi akademik, relasi sosial, finansial, kesehatan dan fungsi kehidupan lain yang penting". Selain itu dampak negatif lain dari kecanduan bermain game online juga menyebabkan rusaknya moral remaja sekarang ini. Maraknya pelecehan seksual, perkelahian antara siswa dengan guru dan percakapan vulgar anak-anak dan remaja menjadi hal yang dianggap biasa.

Game online sudah menjamur disetiap daerah yang ada di Kota Banjarbaru. Permainan tradisional yang dulunya menjadi permainan favorit disetiap pelosok daerah, sekarang telah hilang digantikan oleh game online dan game elektronik. Dilihat dari manfaatnya, permainan tradisional lebih banyak memberikan manfaat dibandingkan dengan permainan game online. Permainan tradisional yang mengandalkan 
seluruh anggota fisik, sudah tentu memberikan manfaat kesehatan bagi orang yang memainkannya, yaitu menjadikan tubuh lebih sehat, kuat dan bugar. Selain itu didalam permainan tradisional juga terdapat pelajaran berupa nilai-nilai kehidupan bermasyarakat, seperti sportivitas, kerjasama, bertanggung jawab, jujur, adil, belajar memanajemen konflik, belajar memecahkan masalah dan lain-lain. Direktorat Nilai Budaya dalam Kurniati (2016) mengatakan bahwa "setiap permainan rakyat tradisional sebenarnya mengandung nilai-nilai yang dapat dimanfaatkan sebagai sarana pendidikan anak-anak. Permainan rakyat tradisional selain dapat memupuk kesatuan dan persatuan juga dapat memupuk kerjasama, kebersamaan, kedisiplinan dan kejujuran.

Itulah gambaran yang sekarang ini terjadi pada anak-anak, remaja bahkan orang dewasa yang ada di Kalimantan Selatan khususnya di Kota Banjarbaru. Masuknya budayabudaya luar ke Indonesia menjadi penyebab merosotnya mental, moral dan karakter generasi penerus bangsa terutama di Kota Banjarbaru. Sudah menjadi tanggung jawab kita semua sebagai warga negara Indonesia khususnya di Kota Banjarbaru untuk memperbaiki hal itu. Karang taruna mempunyai tanggung jawab lebih sebagai wadah pengembangan generasi muda yang memiliki tugas pokok untuk menanggulangi berbagai masalah kesejahteraan sosial terutama yang dihadapi generasi muda, baik yang bersifat preventif, rehabilitatif maupun pengembangan potensi generasi muda di lingkungannya yang dilaksanakan secara bersama sama dengan pemerintah dan komponen masyarakat lainnya. Maka untuk mewujudkan itu semua, perlu didukung oleh sumber daya manusia yang bermoral, berkarakter, beragama dan sehat rohani serta jasmani.

\section{Permasalahan yang Dihadapi}

Ada beberapa permasalahan yang dihadapi oleh Karang Taruna Puskopad, Komplek GCIP Hero, Kota Banjarbaru yang berperan sebagai mitra dalam menarik minat para remaja untuk memainkan permainan tradisional dizaman sekarang ini. Permasalahan tersebut antara lain adalah:

1. Permainan tradisional dianggap sebagai permainan yang kuno dan ketinggalan zaman oleh para remaja masa kini, sehingga malu untuk memainkannya.

2. Para remaja bahkan orang dewasa sudah banyak yang tidak mengetahui jenis-jenis permainan tradisional yang ada di Provinsi Kalimantan Selatan, khususnya di Komplek GCIP Hero, Kota Banjarbaru.

3. Game online menjadi permainan favorit remaja Komplek GCIP Hero, Kota Banjarbaru yang menyebabkan minimnya nilai-nilai sosial remaja masa kini.

Harapannya melalui program kegiatan Pengabdian Kepada Masyarakat ini, bisa membantu Karang Taruna Puskopad sebagi mitra dalam memperkenalkan dan menghidupkan kembali permainan tradisionaldi Kota Banjarbaru. Selain itu juga kegiatan ini diharapkan bisa menumbuhkembangkan kembali moral, mental, karakter dan nilai-nilai kehidupan bermasyarakat para remaja di Komplek GCIP Hero, Kota Banjarbaru. Selain itu Perguruan Tinggi tim pengusul juga sangat 


\section{WAHANA DEDIKASI}

mengapresiasi dan mendukung Pengabdian Kepada Masyarakat ini, karena kegiatan ini merupakan salah satu bentuk aplikasi kami dalam menjalankan Tri Dharma Perguruan Tinggi.

\section{BAHAN DAN METODE}

Seiring perkembangan zaman yang semakin hari semakin modern, memberikan dampak yang menyebabkan tergerusnya budaya khas bangsa Indonesia, yang didalamnya terdapat kearifan lokal masyarakat berupa permainan tradisional. Permainan tradisional yang syarat akan berbagai macam manfaat bagi pertumbuhan anak, semakin menghilang akibat munculnya permainan modern berupa game online dan game eletronik. Hal ini menjadi penyebab anak-anak dan remaja masa kini tidak mengenali permainan tradisional daerahnya masing-masing, khususnya di Komplek GCIP Hero, Kota Banjarbaru, Provinsi Kalimantan Selatan. Selain itu, dampak negatif lain dari munculnya permainan modern berupa game online dan game elektronik menyebabkan merosotnya moral, mental dan karakter para remaja masa kini. Sering kata-kata kasar dan tidak pantas diucapkan ke luar dari mulut remaja masa kini, hal itu mereka lakukan ketika bermain game online dan kerap terjadi dikehidupan bermasyarakat.

Maka dari itu, kami sebagai Tim Pengabdian Kepada Masyarakat, Program Pemberdayaan Masyarakat memberikan solusi awal berupa sosialisasi permainan tradisional kepada para remaja yang ada di Komplek GCIP Hero, Kota
Banjarbaru, Provinsi Kalimantan Selatan. Sosialisasi awal ini akan menjelaskan secara rinci apa itu permainan tradisional, manfaat dan tujuan permainan tradisional, macammacam permainan tradisional serta bagaimana cara bermain permainan tradisional.

Solusi kedua yang kami berikan adalah melaksanakan praktik dengan cara bermain permainan tradisional Kalimantan Selatan dengan sasaran seluruh remaja Karang Taruna Puskopad yang ada di Komplek GCIP Hero, Kota Banjarbaru, Provinsi Kalimantan Selatan serta masyarakat sekitar, mulai dari anak-anak, remaja hingga dewasa. Pada praktiknya kita akan melaksanakan berbagai macam permainan tradisional khas Kalimantan Selatan, yaitu balogo, bagasingan, enggrang, bakiak, kelereng, balap karung dan tarik tambang. Permainan tradisional yang telah disebutkan diatas, syarat akan nilai-nilai yang sangat bermanfaat bagi kehidupan remaja dimasa kini. Terdapat nilai sportivitas, kejujuran, adil, kerjasama, berjiwa ksatria, bertanggung jawab, mengontrol serta memanajemen emosi dan belajar memecahkan masalah (Okilanda, 2021).

Adanya kegiatan ini, maka harapannya adalah para remaja masa kini kembali mengenal dan dapat bermain permainan tradisional serta bisa menerapkan nilai-nilai yang terkandung dalam permainan tersebut dikehidupan bermasyarakat. Dengan penerapan nilai-nilai tersebut dikehidupan bermasyarakat, maka moral, mental dan karakter remaja yang sudah tergerus oleh kemajuan teknologi bisa menjadi lebih baik lagi untuk ke depannya. 


\section{WAHANA DEDIKASI}

Metode yang digunakan dalam merealisasikan Pengabdian Kepada Masyarakat Program Pemberdayaan Masyarakat ini adalah dimulai dari observasi dan mengidentifikasi permasalahan yang terjadi di masyarakat yaitu apa yang menjadi penyebab dari hilangnya permainan tradisional dimasyarakat Kota Banjarbaru dan apa yang menjadi penyebab merosotnya moral, mental dan karakter remaja di sana.

Kemudian dilakukan sosialisasi permainan tradisional, dengan metode ceramah, praktik dan tanya jawab yang bertujuan agar mitra mengetahui apa itu permainan tradisional, manfaat dan tujuan permainan tradisional, macam-macam permainan tradisional serta bagaimana cara bermain permainan tradisional.

Setelah melakukan sosialisasi, maka tahapan berikutnya adalah melaksanakan pelatihan permainan tradisional sebelum mitra melakukan praktik bermain permainan tradisional, tujuannya adalah agar remaja Karang Taruna Puskopad benar-benar menguasai permainan tradisional yang akan dimainkan. Praktik bermain permainan tradisional ini selain diikuti oleh Karang Taruna Puskopad, juga akan diikuti oleh seluruh lapisan masyarakat yang ada di Komplek GCIP Hero, Kota Banjarbaru, mulai dari anak-anak, remaja hingga orang dewasa. Kegiatan ini nantinya akan melaksanakan berbagai macam permainan tradisional khas Kalimantan Selatan, yaitu bakiak, balap karung dan tarik tambang

\section{HASIL DAN PEMBAHASAN}

Kegiatan Pengabdian Kepada Masyarakat ini dilaksanakan pada tanggal 06-07 Maret 2021, Pelaksanaan Pengabdian ini diberi judul "Pemberdayaan Olahraga Rekreasi Melalui Permainan Tradisional Sebagai Upaya Pelestarian Budaya Tradisional Kalimantan Selatan". Kegiatan Pengabdian Kepada Masyarakat ini diikuti oleh 20 orang yang merupakan Karang Taruna Puskopad Komplek GCIP Hero Kota Banjarbaru.

Kegiatan ini dilakukan dengan metode ceramah, praktik dan tanya jawab. Adanya penyampaian materi dengan metode ceramah ini, maka diharapkan para peserta Kegiatan Pengabdian Kepada Masyarakat ini dapat memahami serta menganalisa hal-hal apa saja yang kurang dipahami tentang permainan tradisional, sehingga nantinya apabila ada materi yang kurang dipahami dapat bertanya langsung kepada Tim Pelaksana Pengabdian Kepada Masyarakat.

Ada beberapa hal yang Tim sampaikan kepada para peserta Kegiatan Pengabdian Kepada Masyarakat, yaitu hakikat permainan tradisional, manfaat permainan tradisional, jenis permainan tradisional, hal apa saja yang mempengaruhi hilangnya permainan tradisional dimasyarakat serta bagaimana cara bermain permainan tradisional.

Selanjutnya setelah selesai penyampaian materi secara ceramah, maka para peserta Pengabdian Kepada Masyarakat mempraktikan permainan tradisional dengan diawasi dan dibimbing langsung oleh Tim. Sehingga para peserta dapat merasakan langsung bagaimana bermain permainan tradisional. Kegiatan Pengabdian Kepada 


\section{WAHANA DEDIKASI}

Masyarakat ini diharapkan menjadi solusi bagi masyarakat khusunya anggota Karang Taruna Puskopad Komplek GCIP Hero Kota Banjarbaru dalam menanggulangi hilangnya permainan tradisional ditengah masyarakat di zaman yang serba modern seperti saat ini.

\section{KESIMPULAN}

\begin{tabular}{lcr}
\multicolumn{1}{c}{ Kegiatan } & Pengabdian & Kepada \\
Masyarakat & dengan & judul \\
"Pemberdayaan & Olahraga & Rekreasi
\end{tabular}
Melalui Permainan Tradisional Sebagai Upaya Pelestarian Budaya Tradisional Kalimantan Selatan pada Karang Taruna Puskopad Komplek GCIP Hero Kota Banjarbaru" telah dilaksanakan dengan baik dan berjalan sesuai dengan rencana kegiatan yang telah dijadwalkan. Kegiatan ini mendapat sambutan dan dukungan yang positif dari warga Komplek GCIP Hero Kota Banjarbaru, khususnya Karang Taruna Puskopad. Kegiatan ini diikuti oleh 20 orang yang tergabung dalam Karang Taruna Puskopad. Antusiasme para peserta sangat tinggi dalam mengikuti kegiatan ini. Terbukti dengan keaktifan para peserta untuk bertanya jawab, dan mendiskusikanhal-hal apa saja yang belum mereka pahami tentang permainan tradisional, selain itu para peserta juga sangat antusias dalam mempraktikkan materi permainan tradisional yang telah disiapkan oleh Tim Pengabdian Kepada Masyarakat.

Diharapkan dengan adanya kegiatan Pengabdian Kepada Masyarakat ini, maka anggota Karang Taruna Puskopad Komplek GCIP Hero Kota Banjarbaru akan semakin melestarikan permainan tradisional Kalimantan Selatan, sehingga permainan tradisional tersebut tetap dikenal oleh masyarakat dimasa yang akan datang khususnya para generasi muda. Selain itu juga harapannya adalah permainan tadisional Kalimantan Selatan juga bisa terus dimainkan oleh seluruh lapisan masyarakat yang ada di Komplek GCIP Hero Kota Banjarbaru.

\section{DAFTAR PUSTAKA}

Anggraini, Ratih. 2017. Hubungan Kecanduan Game Online Terhadap Kejadian Astenopia Pada Pelajar SMA Kota Medan. Jurnal Ilmiah Farmasin Kota Medan. Volume 1 Nomor 1, Feb 2017. http://jurnal.uimedan.ac.id/i ndex.php/JURNALFARM ASI/article/view/176. 28 Oktober 2020.

Ghuman, D., \& Griffiths, M. D. (2012). A cross-genre study of online gaming: Player demographics, motivation for play and social interactions among players. International Journal of Cyber Behavior, Psychology and Learning, 2(1), 13-29.

King, D. L., \& Delfabbro, P. H. (2018). Internet gaming disorder: Theory, assessment, treatment and prevention. New York: Academic Press.

Kurniati, Euis. 2016. Permainan Tradisional dan Peranannya dalam Mengembangkan 


\section{WAHANA DEDIKASI}

Keterampilan Sosial Anak.

Jakarta:

PRENADAMEDIA

GROUP.

Okilanda, A., Iswana, B., \& Wanto, S. (2021). Pelatihan Pelatih Fisik

Level I Nasional

Oku. Wahana Dedikasi:

Jurnal PkM IImu

Kependidikan, 3(2), 13-19.

Putra, D. D., Okilanda, A., Arisman, A., Lanos, M. E. C., Putri, S. A. R., Fajar, M., ... \& Wanto, S. (2020). Kupas Tuntas Penelitian Pengembangan Model Borg \& Gall. Wahana Dedikasi: Jurnal PkM IImu Kependidikan, 3(1), 46-55. 